\title{
PENGARUH BAURAN PEMASARAN JASA DAN KUALITAS PELAYANAN KESEHATAN PUSKESMAS BOJONG NANGKA TERHADAP KEPUASAN PASIEN BPJS
}

\author{
THE INFLUENCE OF MARKETING MIX AND SERVICE \\ QUALITY OF PUSKESMAS BOJONG NANGKA AGAINST \\ BPJS PATIENT SATISFACTION
}

\section{Novi Henriyati Rahmi, Sampurno, Wahono Sumaryono}

\author{
Program Magister Farmasi, Fakultas Farmasi, Universitas Pancasila \\ JL. Srengseng Sawah, Pasar Minggu, RT.5/RW.5, Srengseng Sawah \\ Kec. Jagakarsa, Kota Jakarta Selatan, Daerah Khusus Ibukota Jakarta 12640 \\ *Penulis Korespondensi, email : novihenriyati@gmail.com
}

\begin{abstract}
ABSTRAK
Penelitian ini bertujuan untuk menganalisa bagaimana pengaruh bauran pemasaran jasa dalam hal ini produk (product), harga (price), promosi (promotion), lokasi (place), orang (people), bukti fisik / fasilitas fisik (physical evidence), dan proses (process), dan kualitas pelayanan kesehatan dalam hal ini bukti langsung (tangibles), kehandalan (reliability), daya tanggap (responsiveness), jaminan (assurance), dan empati (empathy) di Puskesmas Bojong Nangka Kecamatan Gunung Putri Kabupaten Bogor terhadap kepuasan pasien BPJS. Metode penelitian menggunakan analisis deskriptif metode potong lintang atau cross sectional. Tempat penelitian adalah di Puskesmas Bojong Nangka, Gunung Putri, Bogor. Sampel penelitian berjumlah 100 orang. Teknik pengumpulan data yaitu kuesioner dan observasi. Analisis data penelitian yaitu dengan uji Regresi Linier Berganda dengan hasil $\mathrm{Y}^{1}=1,515+0,064 \mathrm{X}_{1}+0,073 \mathrm{X}_{2}$. Kesimpulan penelitian adalah bahwa bauran pemasaran dan kualitas pelayanan kesehatan berpengaruh secara parsial maupun bersama-sama terhadap kepuasan pasien BPJS.
\end{abstract}

Kata Kunci: bauran pemasaran, kualitas pelayanan, kepuasan

\section{ABSTRACT}

This study aims to analyze how the influence of the service marketing mix in this product, price, promotion, location, people, physical evidence, and the process, and the quality of health services in this case direct evidence (tangibles), reliability, responsiveness, assurance, and empathy at the Bojong Nangka Health Center, Gunung Putri District, Bogor Regency towards patient satisfaction BPJS. The research method used cross sectional or cross sectional descriptive analysis method. The place of research was at the Bojong Nangka Health Center, Gunung Putri, Bogor. The research sample amounted to 100 people. Data collection techniques are questionnaires and observations. Analysis of research data is by the Multiple Linear Regression test with 
$Y 1=1,515+0,064 X 1+0,073 X 2$. The conclusion of the study is that the marketing mix and the quality of health services affect the satisfaction of BPJS patients in partial and both.

Keywords: marketing mix, service quality, satisfaction

\section{PENDAHULUAN}

Pemerintah telah menargetkan UHC (Universal Health Coverage) tercapai pada tahun 2019. FKTP / Faskes Primer mempunyai fungsi sebagai kontak pertama dari peserta BPJS Kesehatan. Banyaknya jumlah FKTP / Faskes Primer yang bekerjasama dengan BPJS dengan fasilitas dan cara pelayanan yang berbeda-beda meskipun pemerintah telah menetapkan Permenkes No. 28 Tahun 2014 sehingga menyebabkan adanya perbedaan mutu layanan yang diterima oleh pasien BPJS sehingga berpengaruh terhadap kepuasan pasien.

Salah satu sasaran yang akan dicapai dalam pengembangan JKN adalah kepuasan pasien. Peta jalan JKN menyebutkan bahwa paling sedikit $75 \%$ pasien menyatakan puas atas pelayanan yang diberikan oleh faskes yang bekerjasama dengan BPJS pada tahun 2014 hingga pada akhirnya diproyeksikan mencapai target kepuasan pasien sebesar 85\% pada tahun 2019. Sementara, dari hasil penelitian sebelumnya didapatkan hasil bahwa terdapat perbedaan kualitas pelayanan antara pasien BPJS dengan pasien umum pada dimensi keselamatan pasien, dimensi efektifitas dan efisiensi pelayanan, dan dimensi pelayanan yang berorientasi pada pasien. Selain itu disebutkan bahwa terdapat perbedaan kepuasan pasien antara pasien BPJS dengan Umum. Pasien BPJS mempunyai kepuasan yang lebih rendah dibanding pasien umum (Pertiwi, 2016).

Penelitian lain menyebutkan bahwa pengguna BPJS Kesehatan 64,7\% tidak puas terhadap Jaminan Kesehatan Nasional. Keluhan pengguna BPJS Kesehatan yang paling utama adalah adalah proses memperoleh kamar rawat inap yang lama. Selain itu, dari hasil wawancara responden diperoleh hasil bahwa ketidakpuasan responden juga disebabkan karena jika mereka membandingkan dengan jaminan kesehatan sebelumnya yaitu Jamsostek, obat-obatan dan pelayanan Rumah Sakit saat ini mengalami penurunan. Menurut responden, harga obat pasien BPJS Kesehatan berbeda dengan harga obat yang responden dapatkan sewaktu menjadi peserta Jamsostek. Menurut responden obat-obatan yang dipakai BPJS hanya berpatokan dari segi harga, bukan manfaat atau kandungan obat di dalamnya. Hal tersebut dikarenakan persepsi masyarakat bahwa sesuatu yang mahal lebih berkualitas (Listiyana, dan Rustiana, 2017).

Program bauran pemasaran jasa mempunyai peranan yang sangat penting sebagai bagian dari strategi dan kebijakan layanan kesehatan untuk mewujudkan kepuasan pasien yang pada akhirnya diharapkan dapat meningkatkan loyalitas. Hal ini sejalan dengan hasil penelitian mengenai analisa pengaruh kualitas pelayanan dan bauran pemasaran terhadap kepuasan pasien rumah sakit umum daerah (RSUD) Wirosaban kota Yogyakarta disimpulkan bahwa kualitas pelayanan berpengaruh terhadap kepuasan pasien, bauran pemasaran berpengaruh terhadap kepuasan pasien, dan kualitas pelayanan dan bauran pemasaran secara simultan berpengaruh terhadap kepuasan pasien (Rifai, 2016).

Penelitian sebelumnya menunjukkan bahwa tarif rawat inap, kualitas pelayanan dan promosi berpengaruh positif dan signifikan terhadap kepuasan pasien rawat inap di RSU Jati Husada Karanganyar (Hartini, 2012). Produk, lingkungan fisik dan profesional berpengaruh terhadap kepuasan pasien. Variabel yang paling berpengaruh adalah 
produk (Sani et al., 2014). Proses adalah variabel yang paling berkorelasi dengan loyalitas pelanggan (Rahayu dan Indriyani, 2015). Ada hubungan antara bauran pemasaran jasa harga, tempat, promosi, petugas, proses, bukti fisik dan layanan fasilitas dengan loyalitas pasien. Tidak ada hubungan antara bauran pemasaran jasa produk dengan loyalitas pasien. Variabel yang paling dominan adalah petugas (Sembor dkk, 2015). Bauran pemasaran jasa (produk, biaya pendidikan, tempat, proses, orang, bukti fisik) dan kualitas pelayanan (bukti langsung, kehandalan, ketanggapan, jaminan, dan empati) berpengaruh terhadap kepuasan mahasiswa (Gultom dkk, 2014). Harga, proses, personal, physical berpengaruh terhadap loyalitas, namun proses tidak berpengaruh terhadap kepuasan. Kepuasan berpengaruh signifikan terhadap loyalitas pasien (Rejeki, 2016).

Bauran pemasaran (marketing mix) merupakan sebuah gabungan strategi pada manajemen pemasaran dalam rangka peningkatan mutu layanan kepada konsumen. Strategi ini meliputi produk (product), harga (price), promosi (promotion), lokasi (place), orang (people), bukti fisik (physical evidence), dan proses (process).Program bauran pemasaran jasa mempunyai peranan yang sangat penting sebagai bagian dari strategi dan kebijakan layanan kesehatan untuk mewujudkan kepuasan pasien yang pada akhirnya diharapkan dapat meningkatkan loyalitas pasien (Hurriyati, 2015).

Kualitas mempunyai hubungan yang erat dengan kepuasan pelanggan. Kualitas dapat mendorong pelanggan untuk menjalin ikatan yang kuat dengan perusahaan. Jasa dipersepsikan baik dan memuaskan jika jasa yang diterima sesuai dengan yang diharapkan. Jika jasa yang diterima melampaui harapan pelanggan, maka kualitas jasa dipersepsikan sebagai kualitas yang ideal. Sebaliknya, bila jasa yang diterima kurang dari yang diharapkan, maka kualitas jasa dipersepsikan buruk. Parasuraman telah melaksanakan penelitian dan mengidentifikasi lima dimensi dalam menilai mutu pelayanan yaitu bukti langsung (tangibles), keandalan (reliability), daya tanggap (responsiveness), jaminan (assurance), dan empati (empathy). Pelayanan kesehatan yang bermutu dapat dikaitkan dengan pelayanan kesehatan yang memuaskan pasien (Sangadji dan Sopiah, 2013).

Kepuasan atau rasa senang yang tinggi dari pasien akan menciptakan ikatan emosional dengan layanan kesehatan yang dipilihnya. Sebaliknya, ketidakpuasan pasien dalam menggunakan layanan kesehatan dapat menyebabkan ketidakpatuhan pasien dalam kegiatan pengobatan, tidak menuruti nasehat dan pindah ke faskes lainny (Nugraheni, 2016). Apabila pasien faskes primer sampai pindah ke faskes primer yang lain, maka tentu saja akan mengurangi besarnya kapitasi yang akan diterima oleh faskes primer tersebut. Dengan demikian, dapat dikatakan bahwa kepuasan pasien menjadi salah satu tujuan dari peningkatan mutu pelayanan kesehatan.

Berdasarkan data peserta BPJS tahun 2014 - Agustus 2017 di Kecamatan Gunung Putri Kabupaten Bogor yang diperoleh dari data BPJS Cabang Bogor dan BPJS Cabang Cibinong, jumlah peserta BPJS yang mengalami penurunan peserta setiap tahunnya adalah pada faskes puskesmas yaitu dari 25\% (tahun 2014) menjadi 18\% (Agustus 2017). Meskipun terjadi penurunan secara persentase namun terjadi kenaikkan jumlah peserta dari 20.653 orang menjadi 29.154 orang. Kenaikkan jumlah peserta BPJS Puskemas Ciangsana paling tinggi dibandingkan puskesmas-puskemas lain untuk periode tahun 2014 sampai Agustus 2017 yaitu sebesar 62\% namun jika dilihat dari jumlah peserta BPJS untuk periode tahun 2016 - Agustus 2018 hanya sebesar 4\% (lebih kecil daripada Puskesmas Bojong Nangka yang sebesar 6\%). Hal ini ada kemungkinan disebabkan karena Puskesmas Ciangsana sudah mengalami kejenuhan dalam menerima peserta BPJS sehingga pasien BPJS mencoba untuk memindahkan pilihan faskes 
primernya ke faskes primer yang lain. Berbeda dengan Puskesmas Bojong Nangka, secara jumlah peserta BPJS semakin tahun semakin bertambah banyak dan pada data pertumbuhan pasien dari periode tahun 2016 sampai Agustus 2017 (pertambahan jumlah peserta BPJS sebesar 6\%).

Dilihat dari persentase selisih jumlah peserta BPJS dari keempat puskesmas di Kecamatan Gunung Putri Bogor, terlihat bahwa Puskesmas Bojong Nangka mengalami peningkatan persentase selisih jumlah peserta BPJS periode 2016 dan 2017 (Agustus) yang tertinggi dibandingkan dengan puskesmas-puskemas lain yaitu sebesar $6 \%$. Peningkatan jumlah peserta ini berhubungan dengan kepuasan peserta BPJS terhadap bauran pemasaran jasa dan kualitas pelayanan kesehatan Puskesmas Bojong Nangka Kecamatan Gunung Putri Kabupaten Bogor. Untuk itu perlu dilakukan penelitian dengan tujuan mengetahui bagaimana pengaruh bauran pemasaran jasa dan kualitas pelayanan kesehatan Puskesmas Bojong Nangka Kecamatan Gunung Putri Kabupaten Bogor baik secara parsial ataupun bersama-sama terhadap kepuasan pasien BPJS.

\section{METODE PENELITIAN}

Penelitian dilakukan dengan menggunakan metode penelitian kuantitatif dengan design penelitian potong lintang atau cross sectional.Teknik pengambilan sample adalah menggunakan teknik Purposive Sampling dikenal juga sebagai sampling pertimbangan yaitu teknik sampling yang digunakan peneliti jika peneliti mempunyai pertimbangan tertentu di dalam pengambilan samplenya atau penentuan sample untuk tujuan tertentu (Riduwan, 2009). Teknik Purposive Sampling ini dipilih karena peneliti bermaksud memilih sample penelitian tertentu yaitu hanya pasien BPJS saja yang dipilih sebagai sampel penelitian. Adapun kriteria inklusi dan eksklusi dalam penelitian ini adalah sebagai berikut:

1. Kriteria inklusi: pasien BPJS yang berusia minimal 18 tahun yang berobat di Puskesmas Bojong Nangka Kecamatan Gunung Putri Kabupaten Bogor.

2. Kriteria eksklusi: pasien BPJS yang berusia minimal 18 tahun yang berobat di Puskesmas Bojong Nangka Kecamatan Gunung Putri Kabupaten Bogor namun tidak bersedia mengisi kuisioner.

Alat dan bahan yang dipakai berupa lembaran kertas yang berisi beberapa pertanyaan dalam bentuk kuisioner yang harus diisi oleh pasien BPJS terpilih sebagai sampel penelitian yang sedang melakukan pemeriksaan kesehatan di Puskesmas Bojong Nangka Gunung Putri Bogor. Jawaban kuesioner dibuat dengan format skala likert (skor skala 1-5) yang disusun sedemikan rupa sehingga memungkinkan pasien BPJS memberikan jawaban dalam berbagai versi tingkatan. Kuisioner yang sudah diisi oleh responden harus segera dikembalikan saat itu juga ke peneliti. Jumlah sampel ditentukan sejumlah 100 orang, merupakan hasil pembulatan perhitungan dengan rumus Slovin $\mathrm{n}=\mathrm{N} /\left(1+\mathrm{N}(\mathrm{e})^{2}\right) ; \mathrm{n}=$ jumlah sampel; $\mathrm{N}=$ jumlah populasi; $\mathrm{e}=$ tingkat kesalahan pada populasi diambil angka $10 \%$. Pada penelitian ini terdapat populasi $(\mathrm{N})$ sejumlah 2224 orang pasien BPJS (PBI 1396 orang dan mandiri 828 orang) di Puskesmas Bojong Nangka pada tahun 2017, dengan grade kesalahan (e) $=10 \%$.

Kuisioner yang digunakan dalam penelitian berupa pertanyaan-pertanyaan yang berhubungan dengan faktor-faktor yang mempengaruhi bauran pemasaran (produk, harga, promosi, lokasi, orang, fasilitas fisik, proses) dan kualitas pelayanan jasa (bukti langsung, kehandalan, daya tanggap, jaminan, perhatian). 
Sebagai referensi dari kuisioner di atas diambil dari (1). kuisioner penelitian sebelumnya dengan judul

Analisis Pengaruh Kualitas Pelayanan dan Bauran Pemasaran terhadap Kepuasan Pasien Rumah Sakit Umum Daerah (RSUD) Wirosaban Kota Yogyakarta, (2). buku ciptaan Ratih Hurriyati yang berjudul Bauran Pemasaran \& Loyalitas Konsumen, (3). buku ciptaan Kotler dengan judul Manajemen Pemasaran : Analisis, Perencanaan, Implementasi, dan Kontrol. Jilid 1, (4) buku ciptaan Fandy Ciptono dengan judul Manajemen Jasa.

\section{HASIL DAN PEMBAHASAN}

Kuisioner sebagai instrumen yang digunakan dalam penelitian ini dilakukan pretest uji validitas dan reliabilitas guna memastikan bahwa pertanyaan-pertanyaan kuisioner valid dan reliabel. Pelaksanaan pretest dilakukan kepada 30 responden sesuai kriteria inklusi sampel.

Hasil uji validitas masing-masing variabel penelitian, semua pertanyan kuisioner dinyatakan valid kecuali ada 2 nomer kuisioner pada variabel bauran pemasaran yang tidak valid yaitu nomer 3.2 dan 3.3. Kuisioner tersebut akan dihapus dari data pernyataan dan tidak akan diperhitungkan sebagai data uji selanjutnya sehingga pernyataan-pernyataan variabel bauran pemasaran jasa dianggap valid dan dapat dipakai sebagai data-data penelitian.

Hasil uji reliabilitas variabel bauran pemasaran jasa, kualitas pelayanan kesehatan, dan kepuasan pasien BPJS menunjukkan bahwa semua pertanyaan kuisioner dianggap reliabel dan dapat dipakai untuk mendapatkan data-data penelitian.

\section{Deskripsi Responden}

Karakteristik 100 orang responden di Puskesmas Bojong Nangka Kecamatan Gunung Putri Kabupaten Bogor dapat dikelompokkan berdasar:

\section{a. Jenis kelamin}

Berdasarkan jenis kelamin responden jumlah terbanyak adalah perempuan dengan jumlah $69 \%$ (69 orang) sedangkan sisanya laki-laki sejumlah $31 \%$ (31 orang).

b. Pendidikan terakhir

Berdasarkan pendidikan terakhir responden jumlah terbanyak adalah tingkat SMA $34 \%$ (34 orang), urutan berikutnya SD 31\% (31 orang), SMP 30\% (30 orang), S1 4\% (4 orang), dan terakhir D3 1\% (1 orang).

c. Pekerjaan

Berdasarkan pekerjaan responden jumlah terbanyak adalah ibu rumah tangga 60\% (60 orang), kemudian disusul karyawan swasta $23 \%$ (23 orang), kelompok lain-lain 10\% (10 orang), wirausaha 6\% (6 orang) dan terakhir PNS 1\% (1 orang). Kelompok lain-lain dalam hal ini mempunyai pekerjaan sebagai buruh, buruh bangunan, guru, pensiunan, pemulung, dan mahasiswa.

d. Kelas kepesertaan BPJS

Berdasarkan kelas kepesertaan BPJS responden jumlah terbanyak adalah kelas 3 sebanyak 70\% (70 orang), disusul oleh kelas 2 sebanyak 17\% (17 orang) dan terakhir kelas 1 sebanyak $13 \%$ (13 orang).

e. Cara pembayaran BPJS

Berdasarkan cara pembayaran BPJS responden jumlah terbanyak adalah dengan membayar secara PBI (Penerima Bantuan Iuran) sejumlah 47\% (47 orang), mandiri $36 \%$ (36 orang), dan terakhir dibayar pemberi kerja sejumlah 17\% (17 orang). 
f. Alasan pemilihan Puskesmas Bojong Nangka sebagai faskes primer

Berdasarkan alasan pemilihan Puskesmas Bojong Nangka sebagai faskes primer responden jumlah terbanyak adalah pilihan atau kesadaran sendiri sejumlah $89 \%$ (89 orang) dan sisanya diajak atau didaftarkan oleh orang lain sejumlah $11 \%$ (11 orang).

\section{Uji Asumsi Dasar}

Uji asumsi dasar yang akan dipakai pada penelitian ini adalah uji normalitas, uji linieritas dan uji homogenitas.

a. Uji normalitas

Dari perhitungan terlihat bahwa nilai sigifikansi semua variabel $<0,05$ sehingga data dinyatakan tidak terdistribusi normal.

b. Uji linieritas

Dari perhitungan terlihat bahwa nilai signifikansi pada Deviation from Linearity variabel bauran pemasaran adalah $0,033(<0,05)$ sehingga data dinyatakan tidak linier dan nilai signifikansi pada Deviation from Linearity variabel kualitas pelayanan kesehatan adalah $0,018(<0,05)$ sehingga data tidak linier.

c. Uji homogenitas

Dari perhitungan terlihat bahwa nilai signifikansi pada Test of Homogeneity variabel bauran pemasaran adalah $0,023(<0,05)$ sehingga data dinyatakan tidak homogeny dan nilai signifikansi pada Test of Homogeneity variabel kualitas pelayanan kesehatan adalah 0,006 $(<0,05)$ sehingga data variabel bauran pemasaran dinyatakan tidak homogen.

\section{Analisis Regresi}

Penelitian ini untuk bertujuan untuk mengetahui pengaruh antar variabel. Karena jumlah variabel independen yang dianalisa sejumlah 2 variabel, maka analisis regresi yang dipergunakan untuk mengukur pengaruh antar variabel pada penelitian ini analisis regresi linier berganda. Pada penelitian ini perhitungan analisis regresi menggunakan SPSS 15.0.

Dari hasil perhitungan diperoleh persamaan regresi linier berganda dengan 2 variabel independen bauran pemasaran dan pelayanan kesehatan adalah sebagai berikut: $\mathrm{Y}^{1}=1,515+0,064 \mathrm{X}_{1}+0,073 \mathrm{X}_{2}$ dengan $\mathrm{F}$ hitung sebesar 29,216 ( > 3,94) dan nilai signifikansinya sebesar $0,000(\leq 0,05)$ maka $\mathrm{H}_{0}$ ditolak sehingga dapat diambil kesimpulan bahwa bauran pemasaran jasa dan kualitas pelayanan kesehatan Puskesmas Bojong Nangka Kecamatan Gunung Putri Kabupaten Bogor secara bersama-sama berpengaruh terhadap kepuasan pasien BPJS.

Diperoleh pula nilai $\mathrm{t}$ hitung pengaruh bauran pemasaran terhadap kepuasan pasien BPJS sebesar 2,199 $(>1,98)$ dan nilai signifikansinya sebesar $0,000(\leq 0,05)$ maka $\mathrm{H}_{0}$ ditolak sehingga dapat diambil kesimpulan bahwa bauran pemasaran jasa Puskesmas Bojong Nangka Kecamatan Gunung Putri Kabupaten Bogor berpengaruh terhadap kepuasan pasien BPJS. Nilai t hitung pengaruh kualitas pelayanan kesehatan terhadap kepuasan pasien BPJS sebesar 3,586 (>1,98) dan signifikansinya sebesar 0,001 $(\leq 0,05)$ maka $\mathrm{H}_{0}$ ditolak sehingga dapat diambil kesimpulan bahwa kualitas pelayanan kesehatan Puskesmas Bojong Nangka Kecamatan Gunung Putri Kabupaten Bogor berpengaruh terhadap kepuasan pasien BPJS.

Hasil penelitian ini sejalan dengan penelitian sebelumnya antara lain: Tarif rawat inap, kualitas pelayanan dan promosi berpengaruh positif dan signifikan terhadap kepuasan pasien rawat inap di RSU Jati Husada Karanganyar (Hartini, 2012); Produk, lingkungan fisik dan profesional berpengaruh terhadap kepuasan pasien. Variabel yang 
paling berpengaruh adalah produk (Sani dkk, 2014), Process adalah variabel yang paling berkorelasi dengan loyalitas pelanggan (Rahayu dan Indriyani, 2015); Ada hubungan antara bauran pemasaran jasa harga, tempat, promosi, petugas, proses, bukti fisik dan layanan fasilitas dengan loyalitas pasien. Tidak ada hubungan antara bauran pemasaran jasa produk dengan loyalitas pasien. Variabel yang paling dominan adalah petugas (Sembor dkk, 2015); Bauran pemasaran jasa (produk, biaya pendidikan, tempat, proses, orang, bukti fisik) dan kualitas pelayanan (bukti langsung, kehandalan, ketanggapan, jaminan, dan empati) berpengaruh terhadap kepuasan mahasiswa (Gultom dkk, 2014); Harga, proses, personal, physical berpengaruh terhadap loyalitas, namun proses tidak berpengaruh terhadap kepuasan. Kepuasan berpengaruh signifikan terhadap loyalitas pasien (Rejeki, 2016).

\section{Analisis Hipotesis}

Untuk mengetahui hubungan antar variabel dilakukan dengan menggunakan uji Spearman dan Kendall's Tau karena berdasar uji normalitas, uji linieritas dan uji homogenitas ternyata data penelitian tidak terdistribusi normal, tidak linier, dan tidak homogen sehingga dilakukan analisa dengan statistik nonparametris.

Dari perhitungan terlihat bahwa nilai signifikansi variabel bauran pemasaran jasa terhadap kepuasan pasien BPJS adalah $0,000(0,000<0,05)$ dan nilai koefisien korelasi 0,573 artinya ada hubungan signifikan antara bauran pemasaran jasa dengan kepuasan pasien BPJS dengan korelasi sedang.

Dari perhitungan diperoleh nilai signifikansi variabel kualitas pelayanan kesehatan terhadap kepuasan pasien BPJS adalah $0,000(0,000<0,05)$ dan nilai koefisien korelasi 0,677 artinya ada hubungan signifikan antara kualitas pelayanan kesehatan dengan kepuasan pasien BPJS dengan korelasi kuat.

\section{Pengaruh Bauran Pemasaran Jasa Puskesmas Bojong Nangka Kecamatan Gunung Putri Kabupaten Bogor terhadap Kepuasan pasien BPJS}

Untuk mengetahui pengaruh sub variabel 7P terhadap kepuasan pasien BPJS dapat dilihat dari nilai koefisien korelasi sub variabel 7P terhadap terhadap kepuasan pasien BPJS seperti tersaji dalam Tabel III. Dari hasil perhitungan, nilai koefisiensi korelasi sub variabel $7 \mathrm{P}$ yang paling besar mempengaruhi kepuasan pasien BPJS adalah sub variabel orang dengan nilai koefisiensi korelasi sebesar 0,590 (korelasi sedang) dan paling kecil mempengaruhi kepuasan pasien BPJS adalah sub variable harga dengan nilai koefisiensi korelasi sebesar 0,255 (korelasi lemah). Sub variabel harga paling rendah pengaruhnya terhadap kepuasan pasien BPJS dengan nilai koefisiensi korelasi sebesar 0,255 (korelasi rendah) karena kemampuan peserta BPJS di Puskesmas Bojong Nangka Kecamatan Gunung Putri Kabupaten Bogor secara ekonomi masih dianggap cukup bagus sehingga mereka tidak mempermasalahkan uang yang harus dikeluarkan untuk biaya kepesertaan BPJS. Hal ini dilihat dari jumlah peserta PBI (Penerima Bantuan Iuran) yang hanya sebesar $47 \%$ masih lebih rendah daripada jumlah peserta PBI secara nasional yaitu sebesar 59,7\% (data per 1 Mei 2018 diambil dari: (Anonim, 2018)

https://databoks.katadata.co.id/datapublish/2018/05/16/berapa-jumlah-peserta-bpjskesehatan

Meskipun begitu terlihat bahwa 3 nilai koefisien korelasi terendah adalah sub variabel harga, tempat, dan promosi. Hal ini dapat diartikan bahwa harga, tempat, dan promosi tidak terlalu signifikan sebagai sub variabel yang diteliti karena harga, 
tempat dan promosi di puskesmas sudah ditetapkan oleh pemerintah dan tidak bisa diubah sesuai kemauan masing-masing puskesmas.

Tabel III. Tabel nilai koefisein korelasi sub variabel 7P terhadap kepuasan Pasien BPJS

\begin{tabular}{ll}
\hline Sub Variabel 7P Terhadap Variabel Kepuasan Pasien BPJS & $\begin{array}{c}\text { Koefisien } \\
\text { Korelasi }\end{array}$ \\
\hline Produk Terhadap Kepuasan Pasien BPJS (X1-1 vs Y) & 0,483 \\
Harga Terhadap Kepuasan Pasien BPJS (X1-2 vs Y) & 0,255 \\
Promosi Terhadap Kepuasan Pasien BPJS (X1-3 vs Y) & 0,301 \\
Tempat Terhadap Kepuasan Pasien BPJS (X1-4 vs Y) & 0,290 \\
Orang Terhadap Kepuasan Pasien BPJS (X1-5 vs Y) & 0,590 \\
Bukti fisik Terhadap Kepuasan Pasien BPJS (X1-6 vs Y) & 0,429 \\
Proses Terhadap Kepuasan Pasien BPJS (X1-7 vs Y) & 0,527 \\
\hline
\end{tabular}

\section{Pengaruh Kualitas Pelayanan Kesehatan Puskesmas Bojong Nangka Kecamatan Gunung Putri Kabupaten Bogor terhadap Kepuasan Pasien BPJS}

Untuk mengetahui pengaruh sub variabel kualitas pelayanan kesehatan terhadap kepuasan pasien BPJS dapat dilihat dari nilai koefisein korelasi sub variabel kualitas pelayanan kesehatan terhadap kepuasan pasien BPJS seperti terlihat pada Tabel IV. Hasil nilai koefisiensi korelasi sub variabel kualitas pelayanan kesehatan yang paling besar pengaruhnya terhadap kepuasan pasien BPJS adalah sub variabel jaminan dengan nilai koefisiensi korelasi sebesar 0,590 (korelasi sedang) dan yang paling kecil pengaruhnya terhadap kepuasan pasien BPJS adalah sub variabel bukti langsung dengan nilai koefisiensi korelasi sebesar 0,546 (korelasi sedang). Untuk meningkatkan nilai bukti langsung dapat melakukan beberapa cara seperti:

a. Meningkatkan kenyamanan ruang tunggu dan ruang periksa

b. Memastikan alat-alat kesehatan yang digunakan dalam kondisi bai

c. Membersihkan WC atau kamar mandi yang digunakan oleh pasien

Tabel IV. Tabel nilai koefisein korelasi sub variabel kualitas pelayanan kesehatan terhadap kepuasan pasien BPJS

\begin{tabular}{lc}
\hline $\begin{array}{l}\text { Sub variabel kualitas pelayanan kesehatan terhadap } \\
\text { variable kepuasan pasien BPJS }\end{array}$ & Koefisien Korelasi \\
\hline Bukti Langsung Terhadap Kepuasan Pasien BPJS (X2-1 vs Y) & 0,546 \\
Kehandalan Terhadap Kepuasan Pasien BPJS (X2-2 vs Y) & 0,573 \\
Daya Tanggap Terhadap Kepuasan Pasein BPJS (X2-3 vs Y) & 0,586 \\
Jaminan Terhadap Kepuasan Pasien BPJS (X2-4 vs Y) & 0,590 \\
Empati Terhadap Kepuasan Pasien BPJS (X2-5 vs Y) & 0,575 \\
\hline
\end{tabular}


Pengaruh Bauran Pemasaran Jasa dan Kualitas Pelayanan Kesehatan Puskesmas Bojong Nangka Kecamatan Gunung Putri Kabupaten Bogor Terhadap Kepuasan Pasien BPJS

Dari hasil analisa regresi linier berganda, dapat diketahui nilai $\mathrm{F}$ hitung sebesar $29,216(>3,94)$ dan nilai signifikansinya sebesar $0,000(\leq 0,05)$ maka $\mathrm{H}_{0}$ ditolak sehingga dapat diambil kesimpulan bahwa bauran pemasaran jasa dan kualitas pelayanan kesehatan Puskesmas Bojong Nangka Kecamatan Gunung Putri Kabupaten Bogor secara bersama-sama berpengaruh terhadap kepuasan pasien BPJS.

\section{KESIMPULAN}

Bauran pemasaran jasa dan kualitas pelayanan kesehatan berpengaruh baik sendisendiri ataupun secara bersama-sama terhadap kepuasan pasien BPJS.

\section{UCAPAN TERIMAKASIH}

Terima kasih yang tak terhingga kami sampaikan kepada pihak manajemen Puskesmas Bojong Nangka, Gunung Putri, Bogor. Dinas Kesehatan Kabupaten Bogor, dan seluruh jajarannya yang telah memberikan izin dan kesempatan dalam pengambilan data penelitian ini

\section{DAFTAR PUSTAKA}

Nugraheni,G., Putri,L.R., Setiawan,C.D., Wijaya,I.N., 2016, Kepuasan Pasien BPJS Kesehatan Terhadap Kualitas Pelayanan Kefarmasian di Pusat Kesehatan Masyarakat (Analisis Menggunakan Servqual Model Dan Customer Window Quadrant), Prosiding Rakernas dan Pertemuan Ilmiah Tahunan Ikatan Apoteker Indonesia: hal. 198, 204.

Pertiwi,A.A.N., 2016, Analisis Perbedaan Kualitas Pelayanan Pada Pasien BPJS Dan Pasien Umum Terhadap Kepuasan Pasien Di Rawat Jalan RSUD Kota Surakarta. Publikasi Ilmiah Mahasiswa Universitas Muhammadiyah Surakarta: hal. 6-7.

Listiyana,I. dan Rustiana,E.R., 2017, Analisis Kepuasan Jaminan Kesehatan Nasional Pada Pengguna BPJS Kesehatan Di Kota Semarang. Unnes Journal of Public Health: hal. 57.

Rifai,M.I., 2016, Analisis pengaruh kualitas pelayanan dan bauran pemasaran terhadap kepuasan pasien Rumah Sakit Umum Daerah (RSUD) Wirosaban kota Yogyakarta, Tesis, Yogyakarta: Universitas Muhammadiyah Yogyakarta: hal 9495.

Hartini,S., 2012, Pengaruh Tarif Rawat Inap, Kualitas Pelayanan Dan Promosi Terhadap Kepuasan Pasien Di RSU Jati Husada Karanganyar, Naskah Publikasi Tesis, Surakarta: Universitas Muhammadiyah Surakarta.

Sani,A., Indar, Daud,A., 2014, Pengaruh Bauran Pemasaran terhadap Kepuasan Pasien Rawat Inap Rumah Sakit Islam Faisal Makassar. Jurnal Pasca Unhas. Makassar: Universitas Hasanuddin. 
Rahayu, Indriyani,I.G.A.D., 2015, Analisis Korelasi Bauran Pemasaran Terhadap Loyalitas Pelanggan Di Unit Pelayanan Teknis Balai Laboratorium Kesehatan Provinsi Bali, Tesis, Denpasar: Universitas Udayana.

Sembor, Patricia,E.N., Posangi,J., Rattu,A.J.M., 2015, Hubungan Antara Persepsi Pasien Umum Tentang Bauran Pemasaran Jasa Dengan Loyalitas Pasien Di Unit Rawat Jalan Rumah Sakit Siloam Manado, Ejhealth, Manado: Universitas Sam Ratulangi.

Gultom,D.K., Ginting, P., Sembiring,B.K.F., 2014, Pengaruh Bauran Pemasaran Jasa Dan Kualitas Pelayanan Terhadap Kepuasan Mahasiswa Program Studi Manajeman Fakultas Ekonomi Universitas Muhammadiyah Sumatera Utara, $J$ Manajemen \& Bisnis, 14 (01) April 2014.

Rejeki,S., 2016, Pengaruh Bauran Pemasaran Terhadap Kepuasan Dan Loyalitas Pasien Rawat Inap Di Rumah Sakit Umum Daerah Dr Soediran Mangun Sumarso Kabupaten Wonogiri, J Of Human Resources Management And Organizational Behavior, 1(2), ISSN 1979-2700.

Hurriyati,R., 2015, Bauran Pemasaran \& Loyalitas Konsumen, CV Alfabeta, Bandung: hal 17-19,27-30, 47-48, 50-52, 54, 55,58, 59, 61-65.

Kotler,P., Manajemen Pemasaran : Analisis, Perencanaan, Implementasi, dan Kontrol, Jilid , Edisi Bahasa Indonesia dari Principles of Marketing 9e. Jakarta: Penerbit PT. Prenhalindo; 2010: hal. 45,87.

Tjiptono, F., 2008. Manajemen Jasa,Yogyakarta: Andi; 2008, hal 110.

Sangadji,E.M., dan Sopiah, 2013, Perilaku Konsumen, Pendekatan Praktis disertai: Himpunan Jurnal Penelitian, C.V Andi Offset,Yogyakarta: hal. 92-93, 100-101, 116.

Sugiyono, 2015, Statistik Nonparametris untuk Penelitian, Alfabeta, Bandung : hal. 2, $3,13,27,41,55,257-259,267,268,286-288$.

Riduwan, 2009, Pengantar Statistika Sosial, Cetakan kedua, Alfabeta, Bandung: hal. $13,16$.

Priyatno,D., 2016, Belajar Alat Analisa Data Dan Cara Pengolahannya Dengan SPSS, Cetakan kesatu, Penerbit Gava Media, Yogyakarta: hal. 97, 103, 106, 109, 144, $150,218$.

Arikunto,S., 2010, Manajemen Penelitian, Cetakan ke sebelas, Rineka Cipta, Jakarta:hal.262. 